\title{
The stability of a block mattress in a propeller induced jet
}

\author{
G. van Velzen \& M.P.C. de Jong \\ Deltares, Delft, The Netherlands
}

J.P. Quataert

Holcim Nederland, Krimpen aan de IJssel, The Netherlands

H.J. Verheij

Delft University of Technology, Delft, The Netherlands

\begin{abstract}
Propeller jets can have a damaging effect on bed, bank and quay structures. A block mattress is one of the various types of bed protection which can be applied to prevent the development of scour holes and subsequent undermining of bed, bank or quay structures. However, not much is known about the stability of block mattress in propeller induced loads. One of the design guidelines which can be used is the formula by Pilarzcyk, in combination with an expression for the dispersion of the propeller jet. To assess the validity of this approach laboratory experiments were performed on the stability of a block mattress in a propeller jet. The model setup comprised a non-sloping horizontal bed and a single horizontal propeller at a certain elevation above the bed. In the test section ripples were applied to mimic the typical unevenness of the bed. Furthermore, a distinction was made within the test programme between an 'open edge', i.e. an outer edge of the protection, and a 'closed edge', i.e. a transition between mattresses. According to the test results, the presently available design guidelines for the stability of a block mattress in a propeller jet may under predict the required thickness of an open and closed edge of a mattress. Furthermore, these guidelines may not yet cover all related aspects correctly, such as the influence of the height of the propeller and the distinction between an open or closed edge.
\end{abstract}

\section{INTRODUCTION}

Without proper measures propeller jets may cause significant damage to bed, bank and quay structures due to the development of scour holes and subsequent undermining of these structures, see Figure 1. To prevent scour, a bed protection is therefore typically required. In practice, various types of bed protection are applied when loads due to propeller jets are expected, such as a loose rock protection, grouted rock protection, a concrete or asphalt mattress or a block mattress. In the present study the stability of a block mattress under the influence of a propeller jet is investigated.

Generally, the guidelines for the design of a scour protection in a propeller jet consist of two steps: 1) determine the maximum load on the bed due to the propeller jet and 2) determine a suitable rock size or mattress thickness based on this load on the bed. These two steps are addressed in the following paragraphs.

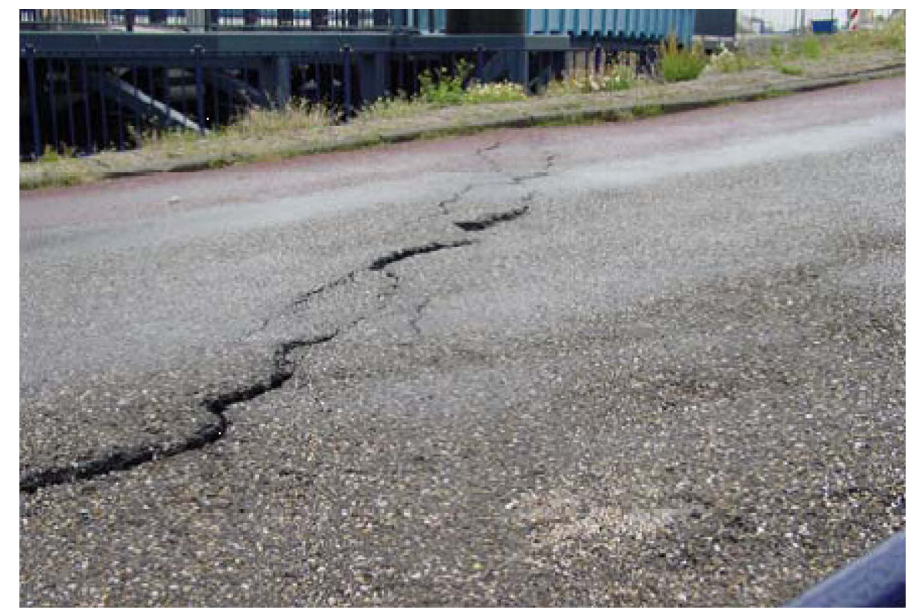

Figure 1. Damage induced by a propeller jet at a quay wall.

\subsection{Load on the bed due to a propeller jet.}

Generally two different approaches can be found in literature which describe the dispersion of the jet and related to that the maximum load on the bed. The first of these approaches is based on the work by Fuehrer, Romisch and Engelke (1981) and is elaborately described in BAW (2010). Another approach is based on the work by Blaauw \& Van de Kaa (1978) and Verheij (1983) and is incorporated in the report of PIANC WG180 (2015). These approaches present a similar expression for the maximum flow 
velocity at the bed due to a propeller jet, see Equation 1 . However different values for the coefficient $\alpha$ are mentioned.

$$
U_{b . \max }=\alpha U_{0} \frac{D_{p}}{h_{p}}
$$

Where $U_{b, \max }=$ the maximum flow velocity at the bed; $\alpha=$ a coefficient; $U_{0}$ the outflow velocity of the propeller; $D_{p}=$ the effective diameter of the propeller and $h_{p}=$ the distance between the propeller axis and the bed.

\subsection{Design of a bed protection in a propeller jet.}

Most information about the stability of a bed protection in propeller jets is related to a loose rock protection. To determine the required stone size the BAW (2010) combine their expression of the maximum load on the bed with an expression which is quite similar to the formula developed by Izbash. The expression of the maximum load on the bed as developed by Blaauw \& Van de Kaa (1978) and Verheij (1983) is frequently combined with the formula of Pilarzcyk, see Equation 2 and [CIRIA, CUR, CETMEF, 2007]:

$$
\Delta D_{n 50}=\phi \frac{0.035}{\psi_{c r}} k_{h} k_{s l}^{-1} \frac{k_{t}^{2} U_{B, \max }^{2}}{2 g}
$$

where $\Delta=$ specific gravity; $D_{n 50}=$ the median stone size; $\phi=$ stability parameter; $\psi_{c r}=$ critical Shields parameter; $k_{h}=$ depth parameter; $k_{s l}=$ slope parameter; $k_{t}=$ turbulence factor and $g=$ gravitational constant. While the formula of Pilarzcyk is originally developed for the stability of loose rocks in a current, factors can be included to account for the load of a propeller jet. Moreover, the Rock Manual also mentioned adjustment factors to account for the stability of a block mattress instead of loose rock in the formula of Pilarzcyk. However, for the combination a propeller jet load and the stability of a block mattress, this design formula has not yet been validated.

In principle, the stability formula of Pilarzcyk is based on the ratio between stabilizing (gravity and friction) and destabilizing forces (lift, shear and drag) on a single stone. When considering mattresses, especially stiff concrete mattresses or asphalt slabs, failure will mainly be introduced by the lift forces on the mattress and a shear or drag force are of minor importance. For the design of a concrete or asphalt mattresses literature therefore provides us with guidelines which relate the required thickness of the mattress to the lift force introduced by the jet flow over the mattress (e.g. PIANC, 2015).

One can argue whether the failure behaviour of a block mattress shows more similarity with loose rock or with a smooth and stiff asphalt or concrete mattress. On the one hand, the blocks in a block mattress are coherent, which is comparable to an asphalt or concrete mattress. On the other hand, the drag forces on these blocks will be more important to consider than the drag forces on a concrete mattress, because a block mattress consists of single blocks with gaps in between. Especially at the edge of the mattress the failure behaviour of a block mattress will show more similarity with loose rock than with a smooth and stiff concrete mattress. Based on this consideration, we therefore consider the application of the formula of Pilarzcyk for the design of block mattresses in propeller induced jets in this study. Physical model tests are performed to obtain a better understanding of the failure mechanisms of block mattress in propeller jet flow and observations about the stability limits are compared with the formula of Pilarczyk.

\section{SETUP OF THE PHYSICAL MODEL}

\subsection{Introduction}

In practice there are countless combinations of types of propellers, configurations of propellers, block mattresses and bathymetries. For the present study one general setup was considered. This general setup consisted of a non-sloping, horizontal bed, a single horizontal ducted propeller and a propeller jet which is directly impacting the block mattress. Furthermore, the ship hull and rudder are not incorporated in the present setup. Because the bed on which the block mattresses are placed will never be completely flat in the field, a ripple pattern was applied to the bed in the model setup. A schematization of this test setup is presented in Figure 2.

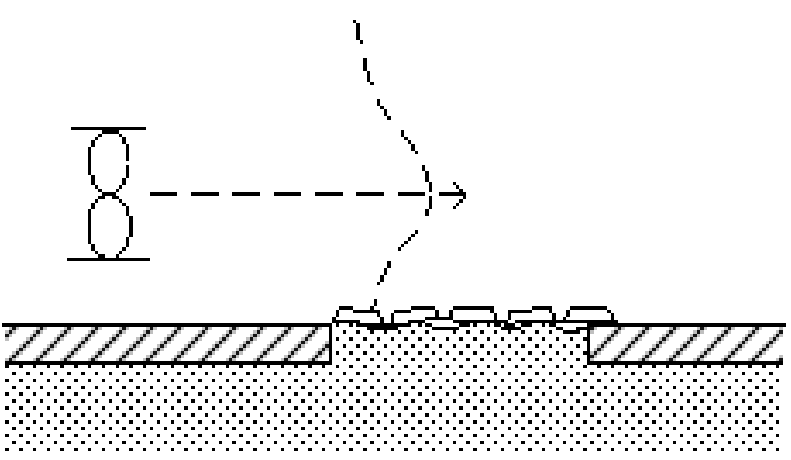

Figure 2. Schematisation of the test setup.

In the test we furthermore distinguish "open" and "closed" edges of the mattresses. An "open" edge is an edge of a mattress at the end of a whole set of mattresses and a "closed" edge is an edge of a mattress which is surrounded by other mattresses. Please note that the mattresses are not joined together in 
this test setup. The formula of Pilarzcyk does not distinguish between an open or closed mattress, most likely because it was assumed that the mattresses would be joined together. To test both the stability of an open and closed edge, the test section contained six individual mattresses, see Figure 3.

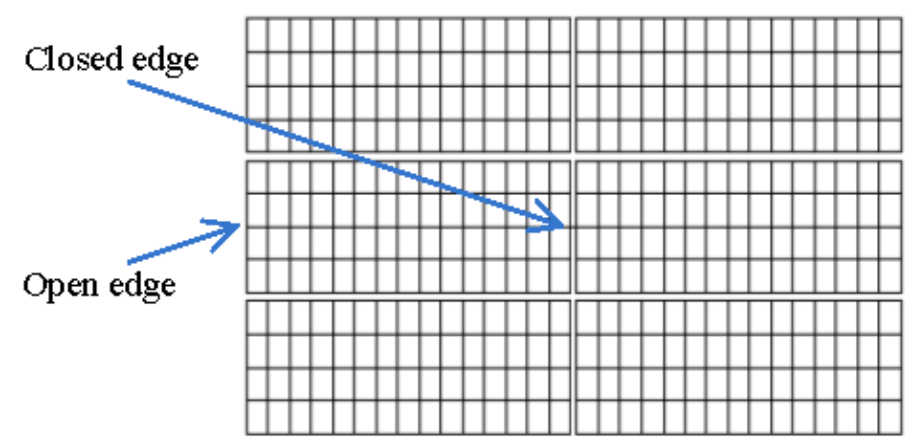

Figure 3. The test section contained six individual mattresses.

The present test series is not aimed at modelling and measuring the load on the bed in a specific prototype situation. It is rather aimed at improving the general understanding of the stability and failure modes of block mattresses under propeller induced loads. Even though there is no specific prototype, the model should represent realistic prototype situations for the model tests to provide valuable data. A representative propeller diameter of $1.6 \mathrm{~m}$, a water depth of almost $5 \mathrm{~m}$ and a distance between the propeller axis and the bed of $1.5 D_{p}$ and $2 D_{p}$ is assumed.

In close collaboration with Holcim Nederland, their GS-VB-15 block mattress is considered in this physical modelling test programme.

\subsection{Test facility and measurements}

The physical model testing programme is performed in Deltares' Atlantic Basin. The Atlantic Basin has a length of $75 \mathrm{~m}$, a width of $8.7 \mathrm{~m}$ and a maximum water depth of approximately $1.1 \mathrm{~m}$. As this basin is equipped with a wave generator and an internal pumping system which can be used to generate a current, this basin is frequently used to simulate coastal and offshore conditions. However, for the present application this basin is used to provide a certain constant water level. The Atlantic Basin is also equipped with a sandy section. In the present test setup parts of this section where covered by concrete plates and other parts served as the test section in which the block mattresses were placed. Figure 4 presents the test setup in Deltares' Atlantic Basin.

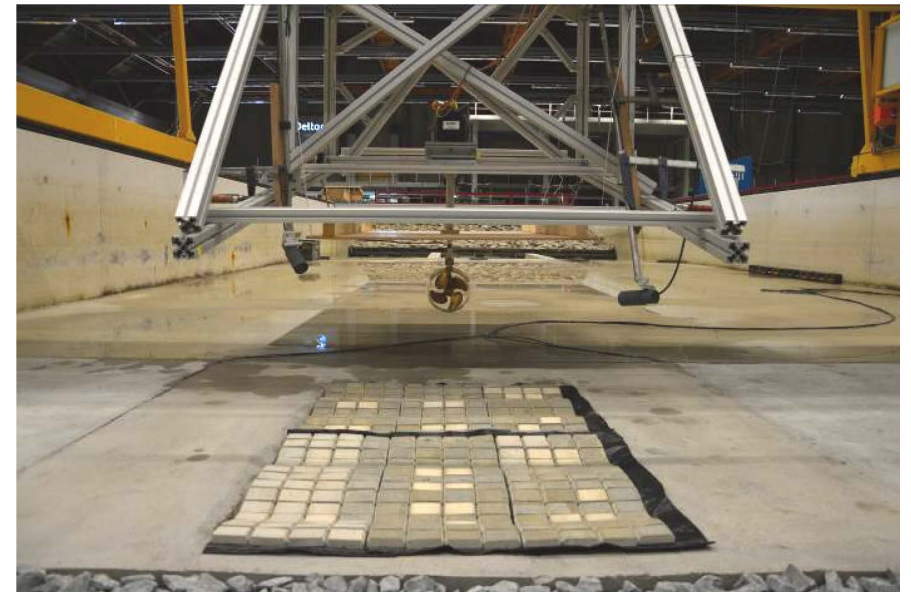

Figure 4. Test setup in Deltares' Atlantic Basin.

With respect to the measurements we distinguish between the hydrodynamic measurements and the measurements of the movement of the block mattresses. The hydrodynamic measurements included the measurements of the water level and the outflow velocity of the propeller. The water level was measured by floaters which were incorporated in the basin walls. The outflow velocity was measured with a Laser Doppler Velocity (LDV) meter. A big advantage of this instrument is that it can measure the flow velocity without interrupting the local flow near the propeller itself. Moreover, in order to limit obstruction of the flow around the propeller by the measurement equipment, the outflow velocity of the propeller was determined as a function of the rotation speed of the propeller prior to the tests, see Section 3.2. Because the rotation speed of the propeller was recorded during the tests, the outflow velocity of the propeller could be determined without any obstruction of the flow. The hydrodynamic measurements are performed with a frequency of $1000 \mathrm{~Hz}$ in order to be able to obtain turbulent properties from the flow velocity signals.

Movement of the block mattress is recorded with an underwater camera. In addition to these camera images, 4 (magnetic) displacement sensors are applied under one block mattress, which could measure a displacement up to approximately $30 \mathrm{~mm}$. Copper plates are attached underneath the geotextile to allow for the detection of the height of the mattress. The displacement sensors were incorporated in the concrete ripple pattern and were placed under the block mattress that was assumed to be most heavily loaded by the propeller jet. Calibration of the displacement sensors took place within the considered test setup. Figure 5 presents the displacement sensors and the copper plates attached to the geotextile of the block mattress. 


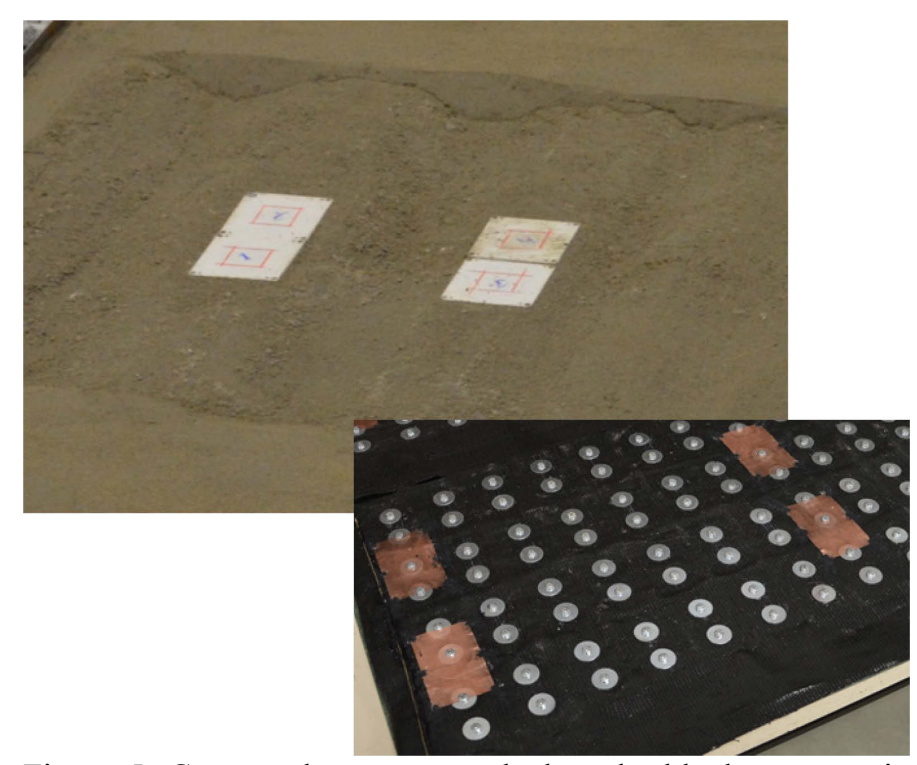

Figure 5. Copper plates are attached to the block mattress in order to measure the displacement of the mattress with the displacement sensors, which are incorporated in the floor.

\subsection{Scale model-propeller}

Deltares has rented a scale model of a ducted propeller from MARIN. The propeller has 4 blades and the shape of the propeller blades is representative for main propellers of cargo vessels. Figure 6 presents the scale model of this ducted propeller. The diameter of this propeller is equal to $204.16 \mathrm{~mm}$. With a representative diameter at prototype scale of $1.6 \mathrm{~m}$, the resulting scale factor is 7.837 :

$n=\frac{D_{p, \text { prot }}}{D_{p, \text { model }}}=\frac{1.6}{0.20416}=7.837$

where $n=$ scale factor; $D_{p, p r o t}=$ the representative propeller diameter at prototype scale; and $D_{p \text {,model }}=$ the propeller diameter at model scale. The length of the nozzle is equal to $102.6 \mathrm{~mm}$, which is roughly equal to $0.5 D_{p}$.

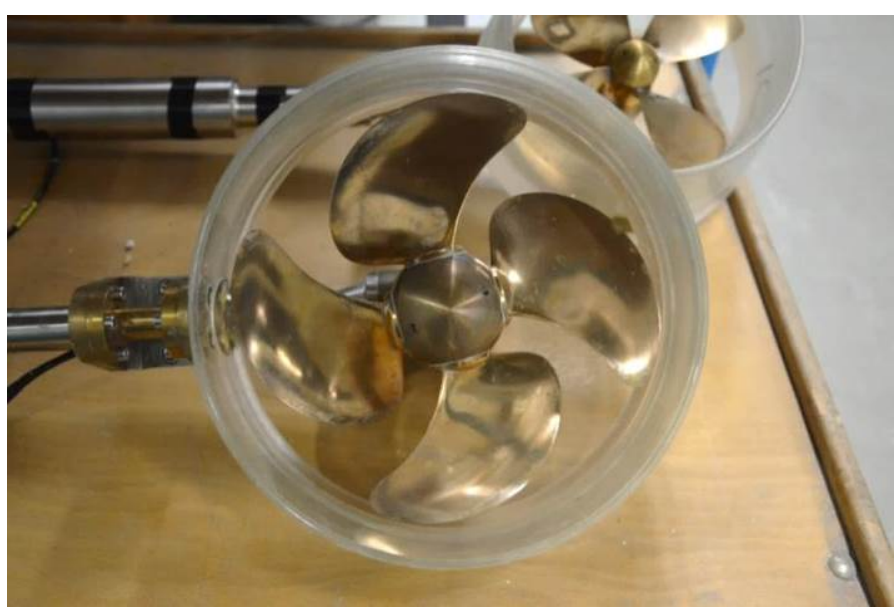

Figure 6 . The scale model of the ducted propeller.

\subsection{Scale model - block mattress}

In the present study we focus on the bulging and flapping of the mattress. Other possible failure mechanisms, such as the rocking of blocks resulting in tear of the geotextile, are not considered here. With this in mind the following properties of the block mattress should be considered in the scaling of the block mattress; weight and shape of the blocks and geotextile, stiffness of the geotextile and permeability of the mattress.

In principle the dimensions of the blocks scale linearly with the scale factor. However, not all dimensions can be scaled directly, due to the fabrication of the small scale mattress. Apart from the geometrical scaling an important aspect to consider in the scaling of the mattress is therefore the underwater weight of the mattress. To obtain a correctly scaled under-water weight of the mattress some corrections have been applied to the linear scaling of the dimensions. These corrections are related to the added mass of the joints between the blocks and the geotextile, the thickness of the geotextile, the density of the concrete and minor simplifications of the shape of the blocks.

On prototype scale the geotextile of the concrete mattresses is very flexible. However, when a similar geotextile is used for a mattress which is approximately 8 times smaller, the geotextile would be relatively stiff. As a relatively stiff geotextile can prevent local flapping or bulging of the mattress, the stiffness of the geotextile should also be considered in the scaling of the mattress. The quantification of the stiffness of the geotextile is based on the situation where the edge of the mat starts to flap, see Figure 7. When a mattress starts to flap, the load exerted on the edge block is such that the block is lifted. As this edge block is connected to the mattress, the block will rotate and 'flap'. The forces preventing this lift and rotation are given by the gravity force of the block and the resistance of the geotextile against bending. The flexibility of the mattress can now be expressed as the ratio between the moment delivered by the gravitational force $\left(\mathrm{F}_{\mathrm{z}} \cdot \mathrm{r}\right)$ and the moment of resistance, or bending moment of the geotextile $\left(\mathrm{M}_{\mathrm{g}}\right)$.

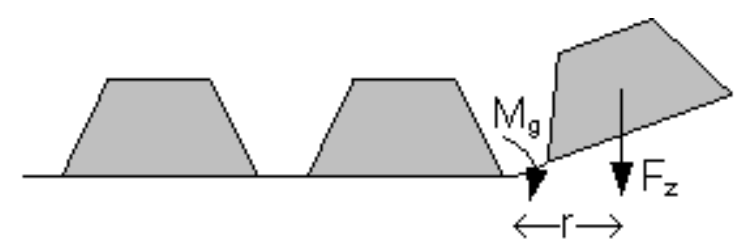

Figure 7. Onset of the failure mechanism "mattress flaps".

The following equation expresses the contribution of the stiffness of the geotextile to the total resistance of the mattress against flapping: 
$\chi=\frac{M_{g}}{M_{g}+F_{z} \cdot r}=\frac{M_{g}}{M_{g}+V \cdot\left(\rho_{c}-\rho_{w}\right) \cdot g \cdot r}$

where $\chi=$ the contribution of the geotextile to the total resistance of the mattress against flapping; $M_{g}=$ the maximum bending moment of the geotextile; $F_{z}$ $=$ the gravity force of the edge block; $r=$ distance between the rotation point of the mattress and the centre of gravity of the edge block; $V=$ volume of the edge block; $\rho_{c}=$ density of the concrete; $\rho_{w}=$ density of water and $g=$ gravitational constant. An indication of the bending moment of the geotextile is obtained by testing the deflection of a strip of the geotextile under its own weight. A relatively narrow strip is chosen, to prevent plate action limiting the deflection. This test showed that the contribution of the stiffness of the geotextile to the resistance against flapping is extremely limited at prototype scale; less than $0.03 \%$. Even though the most flexible geotextile commercially available (PP15 geotextile of Ten Cate) was applied in the scale model, the contribution of the geotextile to total resistance against flapping is approximately $7 \%$ at model scale. This is not equal to the $0.03 \%$ that was found for the prototype scale mattress, but it is the most suitable option for the model scale geotextile. Please note, that apart from a geotextile, other fabrics, such as nylon or cotton could in principle also be applied in the model. Even though these kinds of fabrics might be more flexible than a geotextile, applying these fabrics in the model brings other difficulties with it. For example, fabrics such as nylon or cotton will swell in water, which will decrease the permeability of the mattress during the test. Furthermore, such fabrics might not possess sufficient tensile strength to make the fabrication, transport and application of the model mattresses feasible.

Similar to the flexibility of the geotextile, scaling the permeability of the geotextile exactly right is considered impossible when applying a commercially available fabric in the scale model. The scaling the permeability of the geotextile is therefore aimed at providing conservative results. Regarding the permeability of the geotextile, it is difficult to determine whether a geotextile which is a bit too permeable or a geotextile which is not permeable enough will yield conservative results. When the geotextile is not permeable enough, pressure fluctuations will not penetrate sufficiently, which results in relatively large pressure differences on the geotextile. Consequently, the geotextile will be lifted more easily. Based on this first argument a relatively impermeable geotextile would yield conservative results. However, when the mattress is lifted, water should enter the void under the mattress. As this is difficult when the geotextile is relatively impermeable, actually lifting the mattress would require a larger pressure gradient. This second argument is therefore contradictory to the first argument. However, this second argument is only valid for the middle of the mattress. At the edges of the mattress, water can enter the void under the mattress from the side, without having to penetrate the geotextile. Based on this consideration combined with the fact that failure of a block mattress is generally initiated at the edges, the geotextile applied in the model is chosen such that is has a smaller permeability than the geotextile used in the prototype.

\subsection{Test programme and test routine}

Within the test programme a distinction is made between the stability of an open edge and a closed edge. Moreover, two heights of the propeller are considered, resulting in four tests, see Table 1. For each test several subtests are performed to find the critical outflow velocity (or rotation speed). Each subtest had a duration which was considered large enough to account for the statistics of the highly turbulent propeller jet flow.

Table 1. Test programme

\begin{tabular}{lll}
\hline Test & $\begin{array}{l}\text { Height of the propeller** } \\
{\left[\mathrm{n} \cdot D_{p}\right]}\end{array}$ & $\begin{array}{l}\text { Configuration } \\
\text { B01 }\end{array}$ \\
B02 & 1.5 & $\begin{array}{l}\text { Closed edge } \\
\text { Open edge }\end{array}$ \\
B03 & 2 & $\begin{array}{l}\text { Closed edge } \\
\text { Open edge }\end{array}$ \\
B04 & & Opd \\
\hline
\end{tabular}

* The height of the propeller is defined as the distance between the bed and the propeller axis.

\subsection{Model and scale effects}

Model effects are related to the chosen model setup and the limitations of the facility. The most important model effects of the present test programme are:

- The ships rudder and hull are not incorporated in the model. Both can increase the maximum flow velocity. Furthermore, flow towards the propeller can also result in a pressure gradient above a bed protection. This flow towards the propeller and the resulting pressure gradient will strongly depend on the ship's hull.

- The propeller is not moving. Consequently the combination of rotation speed and thrust which can be reached in the model might not be reached in the field.

- Water is continuously pumped to one side of the basin. To prevent water piling up and the outflow side of the propeller, the basin should be wide enough to permit water flowing around the propeller towards the suction side. This aspect is addressed in Section 3.2. 
Scale effects are related to the downscaling of the situation. The main scale effects of the model tests included:

- The geotextile of the block mattress is a bit too stiff, which increases the resistance of the mat against flapping or bulging.

- The permeability of the mat is a bit too small. At the edge of the mattress the mattress will therefore be lifted more easily.

- For a fixed propeller the most important scale effect is related to the flow along the propeller blades. Viscous effects should not be dominant at model scale, as the viscous forces are not scaled correctly. At model scale the corresponding Reynolds number should exceed approximately $7 \cdot 10^{4}$ (WL Delft Hydraulics, 1985). With the chosen propeller and the applied rotation speeds, the Reynolds number related to the propeller is indeed larger than $7 \cdot 10^{4}$. Scale effect related to the flow along the propeller blades are therefore considered limited.

\section{RESULTS OF THE PHYSICAL MODEL}

\subsection{Introduction}

In this chapter we first present the relation between the outflow velocity and the rotation speed, as determined prior to the actual test series. After that the critical loads as found in the test series are presented. A comparison of these test results with the formula of Pilarzcyk, as well as general remarks on the failure behaviour of the block mattress are addressed in the analysis (next chapter).

\subsection{Test results - Outflow velocity}

Prior to performing the three main test series, the relation between the outflow velocity and the rotation speed of the propeller is determined. By doing so, measuring the outflow velocity during the test was not necessary, as the rotation speed was automatically measured when operating the propeller. This was very advantageous because this prevented a possible disturbance of the flow during the tests.

Three different series of test measurements are performed to measure the relation between the outflow velocity and the rotation speed of the propeller. In the first two series the rotation speed is stepwise increased with relatively small $(25 \mathrm{rpm}$ at model scale) and relatively large steps (50 or $100 \mathrm{rpm}$ at model scale). The third series consisted of individual measurements; after each measurement the rotation speed was dialled back to 0rpm and a next measurement was only started when the water in the basin was still again. Each measurement had a duration of 60s. These different test series were considered to study the reproducibility of the results and the de- pendency of the outcome on the way that the targeted value was reached (at once, or gradually in steps).

Figure 8 presents all measurements of the three different test series, as well as the fitted relation between the outflow velocity and the rotation speed. Please note that the results presented in Figure 8 are based on model scale dimensions.

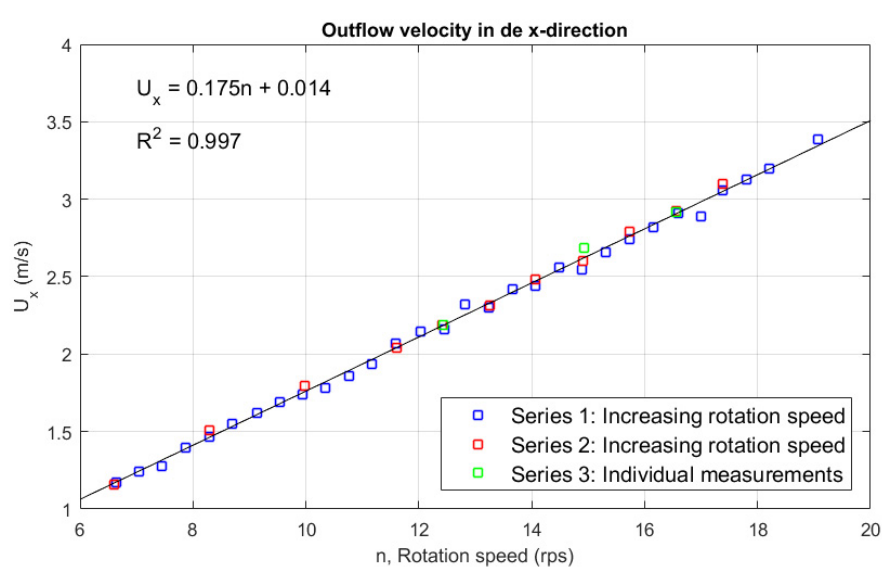

Figure 8 . Relation between the outflow velocity and the rotation speed of the propeller (model scale dimensions).

Figure 8 shows that the outflow velocity of the propeller can be described with a linear function:

$$
U_{0}=0.175 n+0.014
$$

where $\mathrm{U}_{0}$ is the outflow velocity and $\mathrm{n}$ is the rotation speed. For this relation the coefficient of determination, $\mathrm{R}^{2}$, is 0.997 . This means that this linear function fits the measurements almost perfectly. Furthermore, there is no clear difference in the accuracy of the prediction for different rotation speeds or different measurement series. The presented linear relation is therefore very robust. Please note that in this model setup the propeller is 'pumping' water to one side of the basin. To prevent water 'piling up' at this outflow side of the propeller and in order to produce a correct outflow jet, the water should therefore also flow easily from this outflow side to the inflow side of the propeller. There is no difference between the relatively long measurement series, in which the rotation speed was gradually increased, and the individual measurements. From that it can be concluded that the water can flow around the propeller sufficiently well to produce a correct outflow jet, even when the propeller is running for a considerable period of time. In other words, the basin is sufficiently wide and the total volume of water in the basin is sufficiently large to prevent model effects.

\subsection{Test results - critical load of the block mattress}

In the first test series (B01 - closed edge and a propeller height of $1.5 D_{p}$ ) failure of the mattress first occurred at a rotation speed of 1000rpm. Not the 
middle mattress was lifted, but one of the mattresses on the sides, see Figure 9.

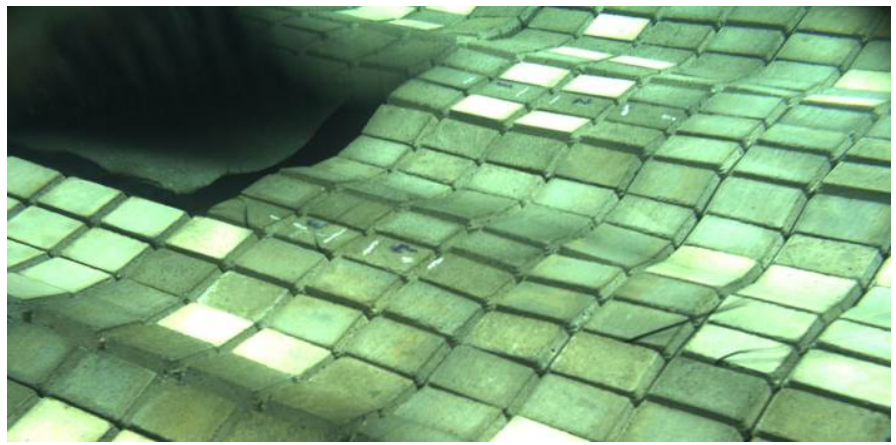

Figure 9. Uplift of one of the mattress during test B01 at $\mathrm{n}=1000 \mathrm{rpm}$.

After repairing the bed protection and running another test with a similar rotation speed $(n=1000 \mathrm{rpm})$, uplift of the mattress did not occur. This difference was probably related to a small difference in placement of the mattress. In a consecutive test in which the rotation speed was increased to $1050 \mathrm{rpm}$, the same mattress was uplifted as observed in Figure 7.

In test B02 the vertical position of the propeller was similar to test B01. However, the three mattresses in the front were removed to simulate the stability of an open edge. With this configuration uplift of the mattress was less abrupt than in the first test series. At a rotation speed of 400rpm large displacement of all three mattresses was observed occasionally.
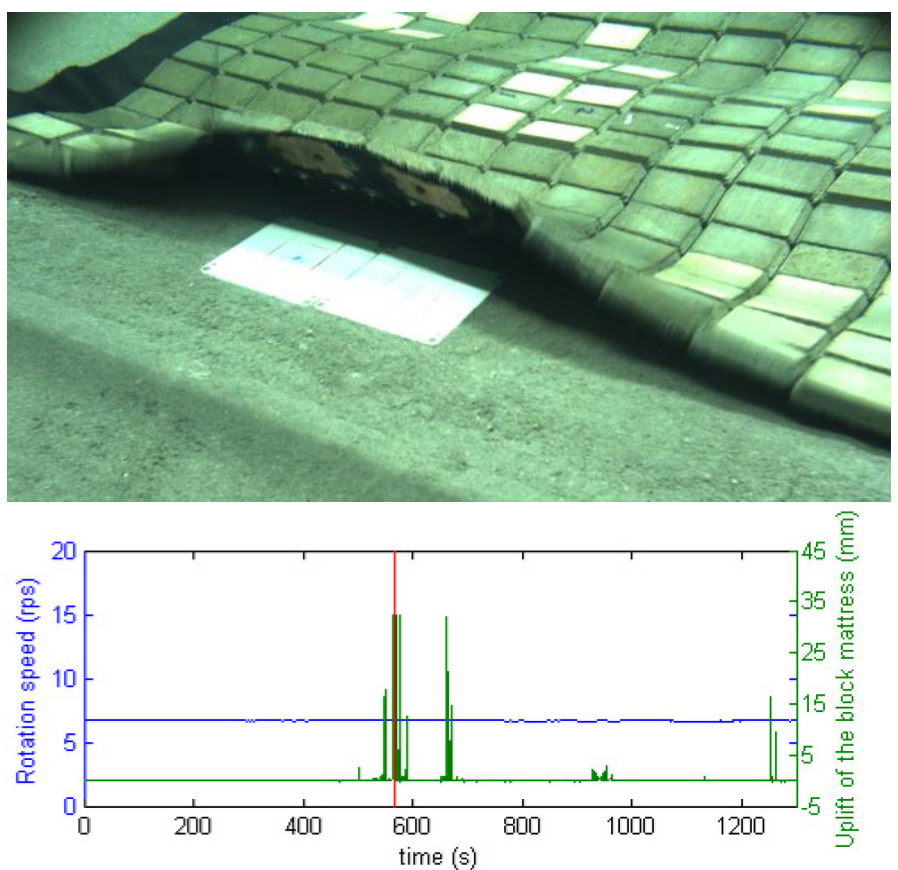

Figure 10. Top: uplift of the three mattresses during test B02 at $\mathrm{n}=400 \mathrm{rpm}$. Bottom: Rotation speed and displacement as measured throughout the test. The red line corresponds with the image above (model scale dimensions).

Figure 10 illustrates uplift of the mattresses during test B02, as well as the displacement of the mattresses and the rotation speed of the propeller as meas- ured throughout the test. The red line within this time series corresponds with the moment that the top image of Figure 10 was captured. This figure shows that even though the mattresses seemed stable during the first 1500 s of the simulation, occasional movement of at least the middle mattress occurred from 1500 s onwards.

The results of test $\mathrm{B} 03$ (closed edge and a propeller height of $2 D_{p}$ ) were similar to the results of test B01 (closed edge and a propeller height of $1.5 D_{p}$ ). Again one of the mattresses on the sides was uplifted at a rotation speed of $1050 \mathrm{rpm}$.

In test B04 (open edge and a propeller height of $2 D_{p}$ ) small occasional uplift of the middle mattress was observed with a rotation speed of 450rpm.

Table 2. Critical load

\begin{tabular}{lllll}
\hline Test & $\mathrm{U}_{0}[\mathrm{~m} / \mathrm{s}]$ & & \multicolumn{2}{c}{$\mathrm{U}_{\mathrm{b}, \max }$ (theory) $[\mathrm{m} / \mathrm{s}]$} \\
& model & field & model & field \\
B01 & 3.0 & 8.4 & 0.6 & 1.7 \\
B02 & 1.1 & 3.1 & 0.2 & 0.6 \\
B03 & 3.0 & 8.4 & 0.5 & 1.3 \\
B04 & 1.3 & 3.7 & 0.2 & 0.6 \\
\hline
\end{tabular}

Table 2 presents the critical flow velocities of the block mattress as observed in the physical model tests. Moreover, this table also shows the maximum flow velocity on the bed as determined with Equation 1. A remarkable difference can be observed between the stability of an open or closed edge. For an open edge (tests B02 and B04) a higher position of the propeller is resulting in a larger critical outflow velocity. For a closed edge (tests B01 and B03) Table 2 shows that failure of the mattress occurred at similar outflow velocities. In other words, the tests indicate that especially for relatively large rotation speeds the effect of the vertical position of the propeller does not have a large influence on the stability of a block mattress.

\section{ANALYSIS}

\subsection{General remarks on the failure behaviour of the block mattress}

Prior to the test, it was expected that a distinction could be made between different failure mechanisms (rocking of the blocks, flapping of the mattress and complete removal of the mattress), which were expected to occur at different rotation speeds. This expectation was based on physical model tests that were performed in 1984 in which the stability of a block mattress in a current was addressed (WL Delft Hydraulics, 1984). However, all tests showed that these failure mechanisms succeeded each other rapidly. Once one of the edge blocks was lifted, the drag force increased and the mattress rolled up. Especially the uplift of a closed edge occurred very sudden, 
without any warning. Moreover, this sudden failure is also related to the highly turbulent flow in the propeller jet. In some tests the mattress did not show any movement throughout the first half of the test, after which it was suddenly completely removed, see Figure 11.

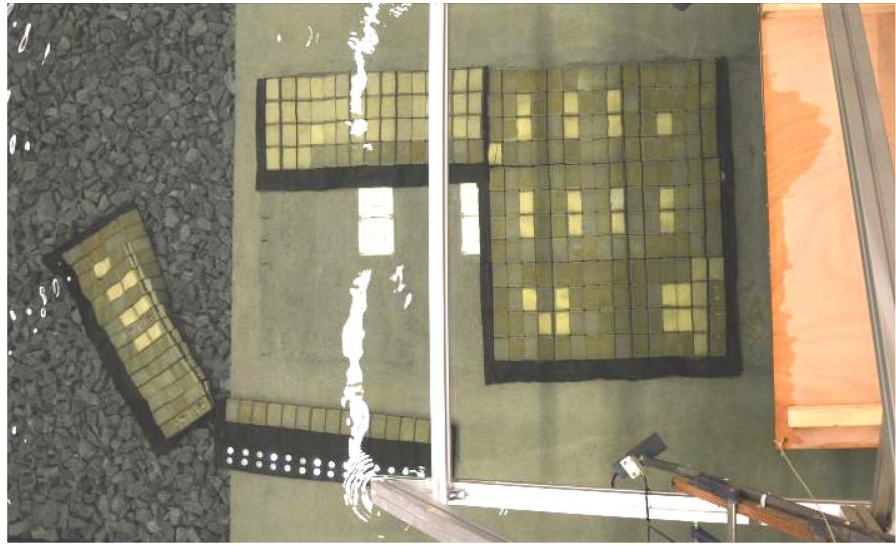

Figure 11. Complete removal of two of the mattresses.

The tests furthermore showed that the stability of a block mattress is very sensitive to the placement of the mattress and a possibly unfavourable position of the edge blocks. A smooth transition between the mattresses will greatly increase the resistance against uplift of these transitional (or closed) edges.

\subsection{Comparison with the formula of Pilarzcyk}

Figures 12 and 13 present a comparison between the critical loads of the block mattresses as found in the physical model test and the design guideline of $\mathrm{Pi}$ larzcyk (Equation 1 and 2). For the formula of Pilarzcyk a turbulence factor $\left(k_{t}^{2}\right)$ of 3-4 is accounted for.

Figure 12 and Figure 13 show that failure of the block mattress occurred in three of the four tests at lower outflow velocities than the critical velocity prescribed by literature. This is regardless of the range of values for $\mathrm{k}_{\mathrm{t}}^{2}$ considered. Only in test B01 the strength of the mattress slightly exceeds the value prescribed by the theory. Especially, for the open edge the under prediction of the required thickness based on the guidelines are quite large. Also the effect of the height of the propeller, as incorporated in Equation 1 does not seem to be as pronounced when comparing Figure 12 with Figure 13. These test results show that the presently available guidelines on the stability of block mattresses in propeller induced loads are not always conservative.

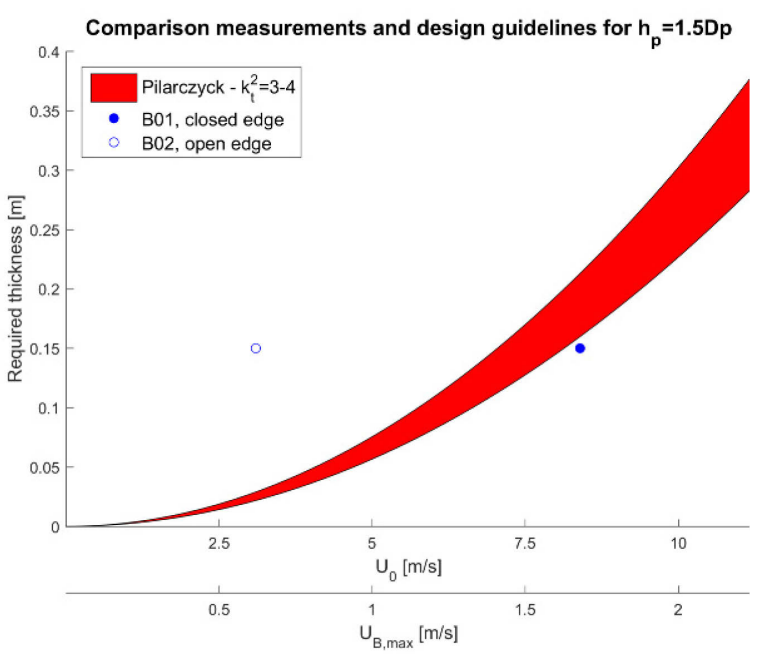

Figure 12. Comparison of measurements and the formula of Pilarczyk for $h_{p}=1.5 D_{p}$.

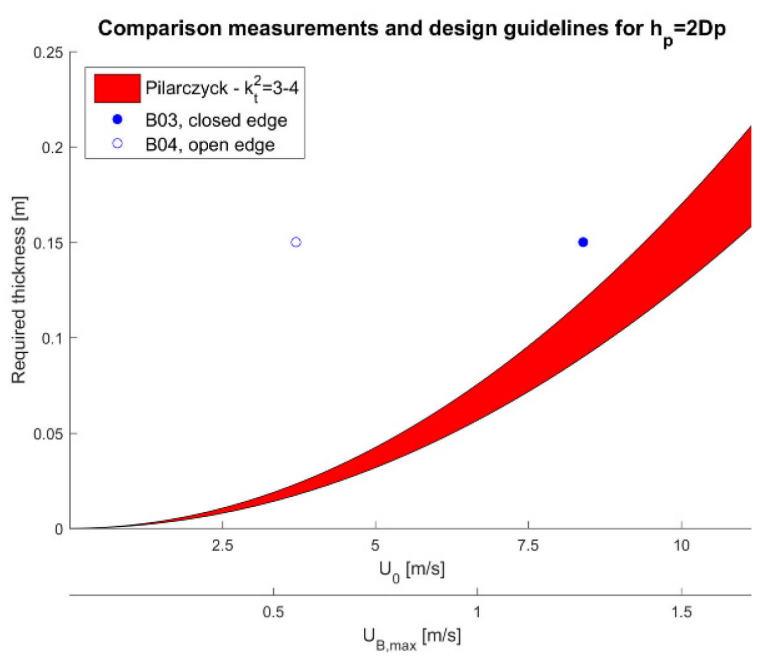

Figure 13. Comparison of measurements and the formula of Pilarczyk for $h_{p}=2 D_{p}$.

\section{CONCLUSIONS AND DISCUSSION}

Even though the amount of tests that could be performed was limited, the model tests showed that the stability of a mattress is very sensitive to the placement of the mattress and a possibly unfavourable position of the edge blocks. Furthermore, the failure process of the mattress occurs quite sudden, especially for the closed (or transitional) edges. This sudden failure is related to the high turbulence levels on the jet flow, as well as the fact that failure of the mattress is a 'snowball-effect'. Once edge blocks are slightly lifted by the flow, the drag forces on these edges increase. This increase in drag forces result in a further uplift of the mattress and eventually in a total removal of the mattress.

According to the test results, the presently available design guidelines for the stability of a block mattress in a propeller jet may under predict the required thickness of an open and closed edge of a mattress. Furthermore, these guidelines may not yet cover all related aspects correctly, such as the influence of the height of the propeller and the distinction between an open or closed edge. 


\section{ACKNOWLEDGEMENTS}

This physical model test programme has been executed within a broader and on-going SBRCURnet project on the distribution of propeller jets and the stability of mitigating measures. This part of the project has been made possible by financial contributions from Holcim Nederland, Rijkswaterstaat, the Port of Rotterdam and the Port of Antwerp. Moreover, Holcim Nederland had also provided the scale model of the block mattresses.

\section{REFERENCES}

BAW. (2010) Principles for the Design of Bank and Bottom Protection for Inland Waterways (GBB). Issue 2010. Karlsruhe, Germany.

Blaauw, H.G. and van de Kaa, E.J. (1978): "Erosion of bottom and sloping banks caused by the screw race of manoeuvring ships." WLDelft Publication no. 202, Proc. 7th Intern. Harbour Congress, Antwerp, May 1978.

CIRIA, CUR, CETMEF (2007): "The Rock Manual. The use of rock in hydraulic engineering" ( $2^{\text {nd }}$ edition), Manual on the Use of Rock.

Fuehrer, M., Römisch, K. and Engelke, G. (1981): “Criteria for dimensioning the bottom and slope protections and for applying the new methods of protecting navigation canals", PIANC, XXVth Congress, Section I, Edinburgh.

PIANC, 2015, Report $\mathrm{N}^{\circ} 180$-Guidelines for protecting berthing structures from scour caused by ships. PIANC Secrétariat Général, Brussels. ISBN 978-2-87223-223-9.

Verheij, H.J., (1983): "The stability of bottom and banks subjected to the velocities in the propeller jet behind ships", 8th Int. Harbour Congress, Antwerp.

WL Delft Hydraulics, 1984, Stormvloedkering Oosterschelde Stabiliteit van de randen van bodemverdedigingen, verslag modelonderzoek, R460-XI / R1431. In dutch.

WL Delft Hydraulics, 1985, Aantasting van dwarsprofielen in vaarwegen, schroefstralen en de stabiliteit van bodem en oevers onder invloed van de stroomsnelheden in de schroefstraal, M1115 deel VII en deel Xa. In dutch. 